\title{
Congenital subependymal giant cell astrocytomas in patients with tuberous sclerosis complex
}

\author{
Katarzyna Kotulska • Julita Borkowska • Marek Mandera • Marcin Roszkowski • \\ Elzbieta Jurkiewicz • Wiesława Grajkowska $\cdot$ Malgorzata Bilska $\cdot$ Sergiusz Jóźwiak
}

Received: 2 August 2014 / Accepted: 3 September 2014 / Published online: 17 September 2014

(C) The Author(s) 2014. This article is published with open access at Springerlink.com

\begin{abstract}
Purpose Subependymal giant cell astrocytoma (SEGA) is a brain tumor associated with tuberous sclerosis complex (TSC). It usually grows in a second decade of life, but may develop in the first months of life. The aim of this work was to establish the incidence, clinical features, and outcome of congenital SEGA in TSC patients.

Methods Cohort of 452 TSC patients was reviewed to identify cases with growing or hydrocephalus producing SEGAs in the first 3 months of life. Clinical presentation, size of the tumor, growth rate, mutational analysis, treatment applied, and outcome were analyzed.

Results Ten (2.2\%) patients presented with SEGA in the first 3 months of life. All of them had documented SEGA growth and all developed hydrocephalus. In eight patients, mutational
\end{abstract}

K. Kotulska $\cdot$ J. Borkowska $\cdot$ M. Bilska $\cdot$ S. Jóźwiak

Department of Neurology and Epileptology, The Children's

Memorial Health Institute, Warsaw, Poland

K. Kotulska $(\bowtie)$

Department of Science, Department of Neurology and Epileptology,

The Children's Memorial Health Institute, Al. Dzieci Polskich 20,

04-730 Warsaw, Poland

e-mail: k.kotulska@ipczd.pl

\section{Mandera}

Department of Paediatric Neurosurgery, Silesian Medical University, Katowice, Poland

M. Roszkowski

Department of Neurosurgery, The Children's Memorial Health Institute, Warsaw, Poland

\section{E. Jurkiewicz}

Department of Radiology, The Children's Memorial Health Institute, Warsaw, Poland

W. Grajkowska

Department of Pathology, The Children's Memorial Health Institute, Warsaw, Poland analysis was done, and in all of them, TSC2 gene mutations were identified. Mean maximum SEGA diameter at baseline was $21.8 \mathrm{~mm}$. Mean SEGA growth rate observed postnatally was $2.78 \mathrm{~mm}$ per month and tended to be higher $(5.43 \mathrm{~mm}$ per month) in patients with TSC2/PKD1 mutation than in other cases. Seven patients underwent SEGA surgery and surgeryrelated complications were observed in $57.1 \%$ cases. One patient was successfully treated with everolimus as a primary treatment.

Conclusions Congenital SEGA develops $2.2 \%$ of TSC patients. Patients with TSC2 mutations, and especially with TSC2/PKD1 mutations, are more prone to develop SEGA earlier in childhood and should be screened for SEGA from birth. In young infants with SEGA, both surgery and mTOR inhibitor should be considered as a treatment option.

Keywords Subependymal giant cell astrocytoma $\cdot$ Tuberous sclerosis complex $\cdot$ Infant $\cdot$ Newborn

\section{Abbreviations \\ SEGA Subependymal giant cell astrocytoma \\ TSC Tuberous sclerosis complex}

\section{Introduction}

Subependymal giant cell astrocytoma (SEGA) is a rare lowgrade brain tumor associated almost exclusively with tuberous sclerosis complex (TSC) $[5,10,11]$. TSC is a genetically determined disorder that affects approximately 1 child in 6000 [28]. It is characterized by the development of benign tumors in various tissues and organs and brain lesions, including SEGAs, subependymal nodules (SENs), and cortical tubers as well as epilepsy and its comorbidities, present the major cause of mortality and morbidity in affected individuals 
$[11,35]$. In TSC, inactivating mutations in either of two genes, $T S C 1$ or $T S C 2$, lead to hyperactivation of mammalian target of rapamycin (mTOR) pathway, which is considered to be a hallmark of the disease $[15,19]$. Mutations in TSC2 were reported to generate a more severe phenotype than mutations in TSC1 [6].

Usually, SEGAs grow in children and adolescents, but there are case reports on neonatal presentation of SEGAs in TSC patients [1, 13, 22, 24, 25, 27, 31-33, 36]. However, there are no data on the incidence of SEGAs in newborns and small infants with TSC and the treatment recommendations for that age group of patients. Currently, there are two possible treatment options for SEGA: surgery or mTOR inhibitor, everolimus, which has been approved for SEGA associated with TSC by FDA and EMA [3, 14]. The data on safety and efficacy of any of these treatments in newborns and infants with SEGA are very limited [7, 18, 20, 25, 32].

The aim of this study was to analyze the incidence, clinical characteristics, and outcome of inborn SEGA in a large cohort of TSC patients who were followed at the Children's Memorial Health Institute, Warsaw.

\section{Material and methods}

The study was approved by The Children's Memorial Health Institute Ethics Committee. The records of TSC patients, who had diagnosis of SEGA prenatally or in the first 3 months of age, were retrospectively reviewed. The inclusion criteria were as follows: diagnosis of SEGA and clinically definite TSC based on Roach's criteria [5]. SEGA was diagnosed when a tumor was characterized by: location near the foramen of Monro, diameter $\geq 1 \mathrm{~cm}$, gadolinium enhancement on neuroimaging, and any documented growth, or hydrocephalus present on baseline neuroimaging. Patients with tumors exceeding $1 \mathrm{~cm}$ in diameter, but not growing or producing hydrocephalus in the first 3 months of life, were not included in the study.

The analyzed data included the following: patient demographics; mutational analysis results; if available, the presenting symptoms; size of the tumor; treatment applied; any adverse events; and results of follow-up neurological examination and neuroimaging studies.

\section{Results}

In a cohort of 452 TSC patients followed at The Children's Memorial Health Institute, Warsaw, Poland, 10 (2.2 \%) children were diagnosed with SEGA in the first 3 months of life.

Five patients $(1.1 \%$ of the whole cohort, $50 \%$ of patients with inborn SEGA) presented with hydrocephalus at baseline, and in all 10 patients, significant tumor growth was observed in the first 3 to 6 months of life. There were eight boys and two girls in this group. Two patients presented clinical symptoms attributed to brain tumor: early focal seizures (one case) or hemiparesis (one case). Table 1 presents clinical data of the patients.

Eight patients had mutational analysis performed and in all of them, mutation in TSC2 gene was identified. Three of these mutations $(37.5 \%)$ were deletions disrupting not only TSC2 gene but also adjacent $P K D 1$ gene, causing polycystic kidney disease in these patients.

Mean maximum SEGA diameter at baseline was $21.8 \mathrm{~mm}$. Figure 1 presents a patient with 13-mm SEGA in the first week of life. Mean SEGA growth rate observed postnatally was $2.78 \mathrm{~mm}$ per month. Mean SEGA size increased by $5.43 \mathrm{~mm}$ per month in patients with TSC2/PKD1 mutations and by 1.76 and $1.35 \mathrm{~mm}$ in patients with other TSC2 mutations and in genetically not tested patients, respectively. The differences were not statistically significant.

Seven patients underwent SEGA surgery. Five patients had surgery during infancy (two at the age of 6 weeks, one at the age of 4 months, one at the age of 8 months, and one at the age of 18 months). These patients were followed by brain ultrasound performed monthly and brain MRI performed every 36 months, and SEGA surgery was done when enlargement of ventricles was seen. In all of them, shunt was applied either before (in two patients) or concomitantly (three patients) with tumor resection.

Two patients had SEGA surgery at the age of 5 and 6 years, respectively, both presented with acute hydrocephalus at that time. In both patients, shunt was placed concomitantly with brain tumor resection. In all operated patients, histopathological diagnosis of SEGA was confirmed.

SEGA was removed totally in six out of seven operated patients. In all of them, no tumor regrowth was observed during follow-up of 144.3 months (range 18-180 months). One patient, in whom SEGA was removed subtotally, required several additional surgeries for regrowing tumor and eventually mTOR inhibitor was introduced with significant improvement.

Three patients had no surgery. Two of them are still infants (6 and 4 months of age) and are followed with serial neuroimaging studies. In one patient, mTOR inhibitor (everolimus) was introduced at the age of 12 months. In this case, SEGA size decreased by $50 \%$ during 4 -year follow-up and the patient is still on treatment.

Surgery-related complications were observed in four patients $(57.1 \%$ of operated cases). Three surgeries were uneventful. The complications included the following: persistent hemiparesis (four patients) and visual impairment (one case).

Five of operated patients developed contralateral SEGA in 18 months to 12 years after the first surgery. Three of them required second surgery, and two were given medical treatment with everolimus. 


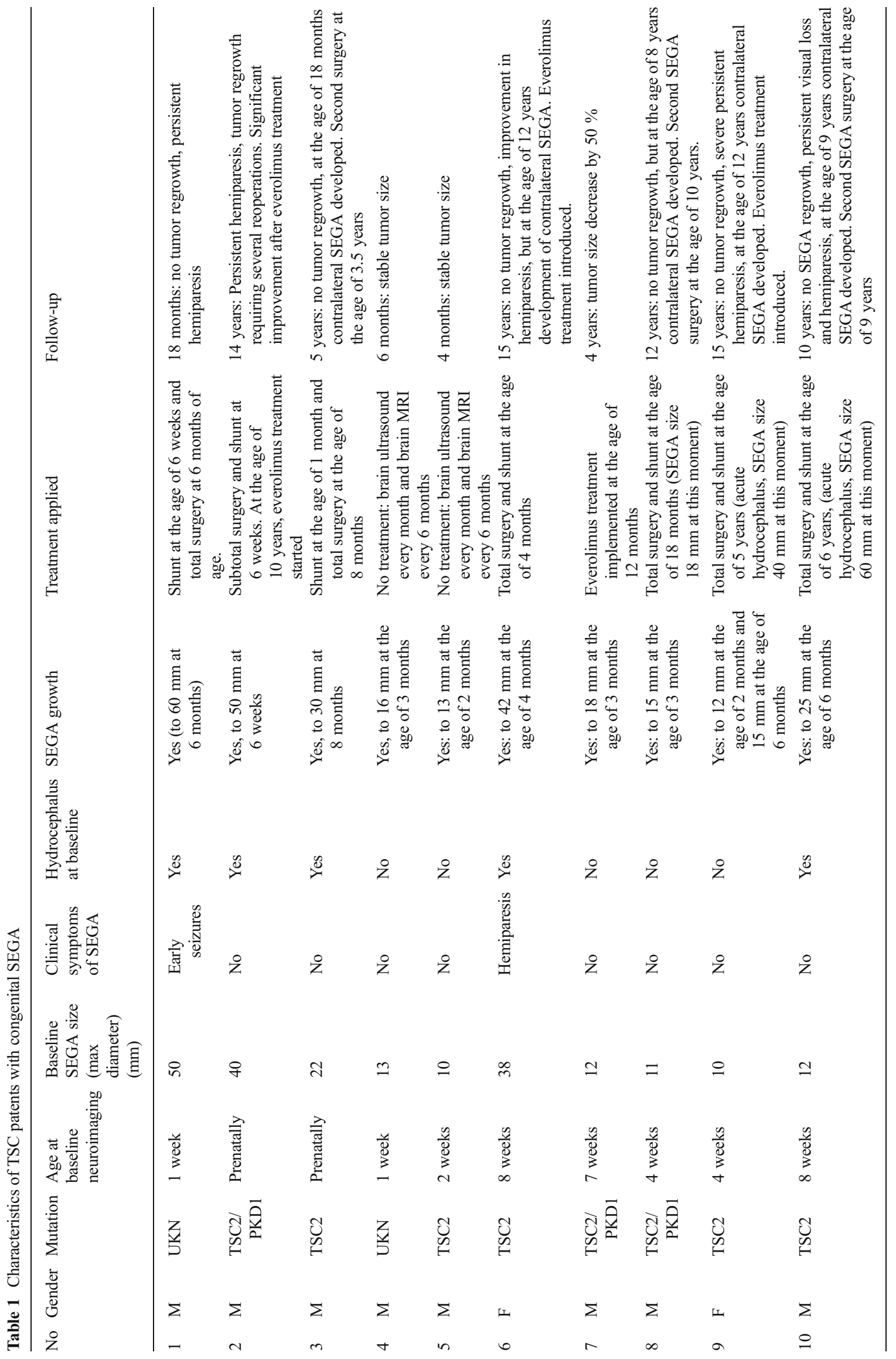




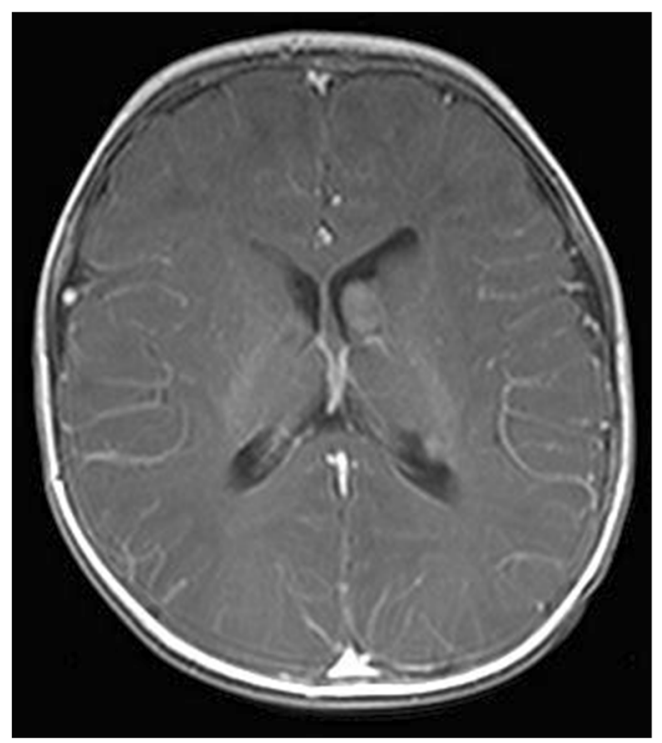

Fig. 1 Brain MRI showing SEGA located near the right foramen of Monro and causing hydrocephalus in a 1-week-old patient with TSC

Altogether, four patients were treated with everolimus: either as primary treatment (one patient) or because of tumor regrowth (one case) or because of new SEGA development (two patients). No new tumor growth was observed in any of patients treated with everolimus.

\section{Discussion}

SEGAs are the most common brain tumors occurring in up to $20 \%$ of the TSC patients, usually in the first two decades of life $[6,23,35]$. They are typically located on the surface of the lateral ventricle of the brain, and thus, while growing, they extend into the lateral ventricle and can obstruct the foramen of Monro and flow of CSF, causing hydrocephalus $[8,10]$. SEGAs usually grow slowly, and the mean age they present clinical symptoms or cause hydrocephalus is 9.7 years $[16,26$, 29, 37]. However, in rare cases, rapid significant increase in tumor size was observed, especially in the youngest children $[12,17]$. There are also reports on SEGA growth in newborns and fetuses [13, 31, 33]. Histopathologically, some SEGAs in very young children may present features of malignancy, which are not typical for this type of tumor [12].

This is the first analysis of incidence, clinical features, and outcome of neonatal SEGA in TSC individuals. In our large cohort of TSC patients, congenital SEGA was present in 10 cases $(2.2 \%)$. It is important to note that in this report, inborn SEGA was recognized only in patients in whom either hydrocephalus associated with SEGA or significant tumor growth within the first 3 months of age was documented. It cannot be excluded that some cases of congenital SEGA, which were asymptomatic at birth and grew slowly, were overlooked in early infancy and diagnosed later in life. In our group of patients with early diagnosed SEGA, two had surgery postponed to the age of 5 and 6 years, respectively. They required surgery because of huge tumors and acute hydrocephalus, but they had been asymptomatic up to this moment. One of those patients was lost from follow-up for 4 years, and the parents of the other one did not give consent for surgery as long as the patient had no SEGA symptoms. Considering those cases, the possibility that more cases of congenital SEGAs are not being recognized seems to be likely.

Although rare, congenital SEGAs present significant clinical problem. Surgical treatment of brain tumors in young infants remains a challenging endeavor, and even in benign tumors, mortality and morbidity in these patients is higher than that in other pediatric age groups [21]. In our study, there were no deaths, but $57 \%$ of operated patients experienced significant neurological deficits associated with surgery. This is consistent with our previous reports, showing that age $<3$ years is a risk factor for SEGA surgery complications [16].

Five of our operated patients had SEGA resection and shunt implantations performed during one surgery, and in two patients, shunt was placed earlier (at the age of 4 and 6 weeks), and SEGA surgery was postponed to the age of 8 and 6 months, respectively. Both approaches were associated with risk of surgery-related sequelae, although it should be noted that the patient who had shunt prior to SEGA surgery at the age of 6 months was the one to have the largest tumor in the cohort (60 $\mathrm{mm}$ in diameter) and SEGA size exceeding $4 \mathrm{~cm}$ is an important risk factor for surgery complications [4, $16,30]$. Therefore, it cannot be excluded that in some cases, earlier shunt implantation and postponed SEGA resection might be beneficial.

Six out of seven operated patients in this cohort had total SEGA surgery and in one, partial resection was performed. Accordingly, to other reports $[2,16,30]$, no tumor regrowth was observed after total SEGA surgery, but several additional surgeries were performed in a patient after partial resection. It should be noted, however, that in five patients, contralateral SEGA developed over the next 1.5 to 12 years. This finding suggests that patients who had one SEGA might require more frequent neuroimaging studies than patients who had never had such tumor.

In our cohort of newborns with SEGA, TSC2 mutations, including TSC2 large deletions affecting PKD1 gene, were identified in all of patients who had mutational analysis done. No patient with inborn SEGA had TSC1 mutation. It is consistent with our previous studies showing that SEGA develop significantly more earlier in individuals with TSC2 mutations than in TSC1 mutation patients [16]. Moreover, this study shows that patients with large genomic mutations affecting both TSC2 and PKDl genes are at significantly higher risk of early development of SEGA than patients with other mutations in TSC2 genes. TSC2/PKD1 mutations account for $2-3 \%$ 
of all TSC cases [6, 34], but in our cohort, these mutations were found in $30 \%$ of patients. Our results indicate that patients with polycystic kidneys and TSC should be screened for SEGA from birth.

In this study, SEGAs in patients with PKD1/TSC2 mutations tended to grow more rapidly than in patients with other TSC2 mutations and patients with unknown mutations. The differences between the groups were not significant ( $p=0.19$ and 0.21 , respectively) but it was likely associated with small groups. Nevertheless, patients with large PKD1/TSC2 mutations and SEGAs should be followed with frequent neuroimaging studies.

Recently, an mTOR inhibitor, everolimus, was approved by EMA and FDA for medical treatment of SEGA associated with TSC $[9,14,18]$. The data on safety of everolimus in infants and young children is very limited, but in a small cohort of TSC children below 3 years of age, such treatment was reported to be safe and effective [17]. In this study, one patient had everolimus introduced as a primary treatment for SEGA and one as a adjuvant therapy after partial SEGA resection, and two additional patients everolimus was started because of the development of contralateral tumor. All these patients are continuing treatment. The patient who is given everolimus for primary treatment of SEGA at the age of 12 months has been being followed for 4 years. SEGA size in this child decreased by $50 \%$. None of the patients treated with everolimus developed new tumor, but it should be noted that in two of them, everolimus was introduced because of contralateral tumor growth. The possibility that medical treatment with mTOR inhibitor might prevent or reduce the risk of SEGA development requires further studies.

In conclusion, we showed that congenital SEGA develops $2.2 \%$ of TSC patients. Patients with TSC2 mutations, and especially with TSC2/PKD1 mutations, are more prone to develop SEGA earlier in childhood and should be screened for SEGA from birth. In young infants with SEGA, both surgery and mTOR inhibitor should be considered as a treatment option.

Acknowledgments We thank Natalia Maćkowiak for her kind technical support.

Conflict of interest All authors declare no financial relationships relevant to this article to disclose. All authors declare no conflict of interest to disclose.

\section{Funding NCN grant \#UMO-2013/09/N/NZ7/02125.}

Open Access This article is distributed under the terms of the Creative Commons Attribution License which permits any use, distribution, and reproduction in any medium, provided the original author(s) and the source are credited.

\section{References}

1. Adriaensen MAEP, Schaefer-Prokop CM, Stijnen T, Duyndam DAC, Zonnenberg BA, Prokop M (2009) Prevalence of subependymal giant cell tumors in patients with tuberous sclerosis and a review of the literature. Eur J Neurol 16:691-696

2. Amin S, Carter M, Edwards R (2013) The outcome of surgical management of subependymal giant cell astrocytoma in tuberous sclerosis complex. Eur J Paediatr Neurol 17:36-44

3. Beaumont TL, Limbrick DD, Smyth MD (2012) Advances in the management of subependymal giant cell astrocytoma. Childs Nerv Syst 12(28):963-968

4. Berhouma M (2010) Management of subependymal giant cell tumors in tuberous sclerosis complex: the neurosurgeon's perspective. World J Pediatr 6(2): 103-110

5. Curatolo P, Bombardieri R, Jozwiak S (2008) Tuberous sclerosis. Lancet 372:657-668

6. Dabora SL, Jozwiak S, Franz DN, Roberts PS, Nieto A, Chung J, Choy YS, Reeve MP, Thiele E, Egelhoff JC, Kasprzyk-Obara J, Domanska-Pakiela D, Kwiatkowski DJ (2001) Mutational analysis in a cohort of 224 tuberous sclerosis patients indicates increased severity of TSC2, compared with TSC1, disease in multiple organs. Am J Hum Genet 68:64-80

7. Demir HAI, Ekici F, Yazal Erdem A, Emir S, Tunç B (2012) Everolimus: a challenging drug in the treatment of multifocal inoperable cardiac rhabdomyoma. Pediatrics 130(1):e243-247

8. Di Rocco C, Ianelli A, Marchese E (1995) On the treatment of subependymal giant cell astrocytomas and associated hydrocephalus in tuberous sclerosis. Pediatr Neurosurg 23:115-121

9. Franz DN, Belousova E, Sparagana S, Bebin EM, Frost M, Kuperman R, Witt O, Kohrman MH, Flamini JR, Wu JY, Curatolo P, de Vries PJ, Whittemore VH, Thiele EA, Ford JP, Shah G, Cauwel H, Lebwohl D, Sahmoud T, Jozwiak S (2013) Efficacy and safety of everolimus for subependymal giant cell astrocytomas associated with tuberous sclerosis complex (EXIST-1): a multicentre, randomised, placebo-controlled phase 3 trial. Lancet 381(9861):125-132

10. Goh S, Butler W, Thiele EA (2004) Subependymal giant cell tumors in tuberous sclerosis complex. Neurology 63(8):14571461

11. Grajkowska W, Kotulska K, Jurkiewicz E, Matyja E (2010) Brain lesions in tuberous sclerosis complex. Rev Folia Neuropathol 48(3): 139-149

12. Grajkowska W, Kotulska K, Jurkiewicz E, Roszkowski M, Daszkiewicz P, Jóźwiak S, Matyja E (2011) Subependymal giant cell astrocytomas with atypical histological features mimicking malignant gliomas. Folia Neuropathol 49(1):39-46

13. Hussain NI, Curran A, Pilling D, Malluci CL, Ladusans EJ, Alfirevic Z, Pizer B (2006) Congenital subependymal giant cell astrocytoma diagnosed on fetal MRI. Arch Dis Child 91(6):520

14. Jóźwiak S, Nabbout R, Curatolo P (2013) Management of subependymal giant cell astrocytoma (SEGA) associated with tuberous sclerosis complex (TSC): Clinical recommendations. Eur J Paediatr Neurol 17(4):348-52

15. Kim SK, Wang KC, Cho BK (2001) Biological behavior and tumorigenesis of subependymal giant cell astrocytomas. J Neurooncol 52(3):217-225

16. Kotulska K, Borkowska J, Roszkowski M, Mandera M, Daszkiewicz P, Drabik K, Jurkiewicz E, Larysz-Brysz M, Nowak K, Grajkowska W, Domańska-Pakieła D, Jóźwiak S (2014) Surgical treatment of subependymal giant cell astrocytoma in tuberous sclerosis complex patients. Pediatr Neurol 50(4):307-12

17. Kotulska K, Chmielewski D, Borkowska J, Jurkiewicz E, Kuczyński D, Kmieć T, Lojszczyk B, Dunin-Wąsowicz D, Jóźwiak S (2013) Long-term effect of everolimus on epilepsy and growth in children under 3 years of age treated for subependymal giant cell astrocytoma 
associated with tuberous sclerosis complex. Eur J Paediatr Neurol 17(5):479-85

18. Krueger DA, Care MM, Holland K, Agricola K, Tudor C, Mangeshkar P, Wilson KA, Byars A, Sahmoud T, Franz DN (2010) Everolimus for subependymal giant-cell astrocytomas in tuberous sclerosis. N Engl J Med 363(19):801-1811

19. Kwiatkowski DJ (2003) Rhebbing up mTOR: new insights on TSC1 and TSC2, and the pathogenesis of tuberous sclerosis. Cancer Biol Ther 2(5):471-476

20. Lam C, Bouffet E, Tabori U, Mabbott D, Taylor M, Bartels U (2009) Rapamycin (sirolimus) in tuberous sclerosis associated pediatric central nervous system tumors. Pediatr Blood Cancer 54(3):476-479

21. Lang SS, Beslow LA, Gabel B, Judkins AR, Fisher MJ, Sutton LN, Storm PB, Heuer GG (2012) Surgical treatment of brain tumors in infants younger than six months of age and review of the literature. World Neurosurg 78(1-2):137-44

22. Medhkour A, Traul D, Husain M (2002) Neonatal subependymal giant cell astrocytoma. Pediatr Neurosurg 36(5):271-4

23. Michelozzi C, Di Leo G, Galli F, Silva Barbosa F, Labriola F, Sardanelli F, Cornalba G (2013) Subependymal nodules and giant cell tumors in tuberous sclerosis complex patients: prevalence on MRI in relation to gene mutation. Childs Nerv Syst 29(2):249-254

24. Mirkin LD, Ey EH, Chaparro M (1999) Congenital subependymal giant-cell astrocytoma: case report with prenatal ultrasonogram. Pediatr Radiol 29(10):776-80

25. Mlczoch E, Hanslik A, Luckner D, Kitzmüller E, Prayer D, MichelBehnke I (2014) Prenatal diagnosis of a gigantic cardiac rhabdomyoma in tuberous sclerosis complex - a new therapeutic option with Everolimus. Epub ahead of print, Ultrasound Obstet Gynecol

26. Nabbout R, Santos M, Rolland Y, Delalande O, Dulac O, Chiron C (1999) Early diagnosis of subependymal giant cell astrocytoma in children with tuberous sclerosis. J Neurol Neurosurg Psychiatry 66: 370-375
27. Oikawa S, Sakamoto K, Kobayashi N (1994) A neonatal huge subependymal giant cell astrocytoma: case report. Neurosurgery 35(4):748-50

28. Osborne JP, Fryer A, Webb D (1991) Epidemiology of tuberous sclerosis. Ann N Y Acad Sci 615:125-127

29. Pascual-Castroviejo I, Pascual-Pascual SI, Velázquez-Fragua R, Viaño J, Carceller F, Hernández-Moneo JL, Gutiérrez-Molina M, Morales C (2010) Subependymal giant cell astrocytoma in tuberous sclerosis complex. A presentation of eight paediatric patients. Neurologia 25(5):314-321

30. Pascual-Castroviejo I (2011) Neurosurgical treatment of tuberous sclerosis complex lesions. Childs Nerv Syst 27:1211-1219

31. Phi JH, Park SH, Chae JH, Hong KH, Park SS, Kang JH, Jun JK, Cho BK, Wang KC, Kim SK (2008) Congenital subependymal giant cell astrocytoma: clinical considerations and expression of radial glial cell markers in giant cells. Childs Nerv Syst 24(12):1499-503

32. Prato G, Mancardi MM, Baglietto MG, Janis S, Vercellino N, Rossi A, Consales A, Raso A, Garrè ML (2013) Congenital segmental lymphedema in tuberous sclerosis complex with associated subependymal giant cell astrocytomas treated with mammalian target of rapamycin inhibitors. J Child Neurol

33. Raju GP, Urion DK, Sahin M (2007) Neonatal subependymal giant cell astrocytoma: new case and review of literature. Pediatr Neurol 36(2):128-31

34. Sampson JR, Maheshwar MM, Aspinwall R (1997) Renal cystic disease in tuberous sclerosis: role of the polycystic kidney disease 1 gene. Am J Hum Genet 61:843-851

35. Schwartz RA, Fernandez G, Kotulska K, Jozwiak S (2007) Tuberous sclerosis complex: advances in diagnosis, genetics, and management. J Am Acad Dermatol 57:189-202

36. Tien RD, Hesselink JR, Duberg A (1990) Rare subependymal giantcell astrocytoma in a neonate with tuberous sclerosis. AJNR Am J Neuroradiol 11(6):1251-2

37. Torres OA, Roach ES, Delgado MR (1998) Early diagnosis of subependymal giant cell astrocytoma in patients with tuberous sclerosis. J Child Neurol 13(4):173-177 